\title{
Miniaturized Dual-Band Dual-Mode Microstrip Patch Antenna with Defected Ground Structure for Wearable Applications
}

\author{
Nur Azura Shamsudin ${ }^{1}$, Shaharil Mohd Shah ${ }^{2 *}$ \\ ${ }^{1}$ Faculty of Electrical and Electronic Engineering, \\ Universiti Tun Hussein Onn Malaysia, 86400 Batu Pahat, Johor, MALAYSIA \\ ${ }^{2}$ Advanced Telecommunication Research Center (ATRC), \\ Universiti Tun Hussein Onn Malaysia, 86400 Batu Pahat, Johor, MALAYSIA \\ *Corresponding Author
}

DOI: https://doi.org/10.30880/jeva.2021.02.02.013

Received 22 July 2021; Accepted 18 October 2021; Available online 30 December 2021

\begin{abstract}
This work presents the performance of a miniaturized dual-band dual-mode microstrip patch antenna with Defected Ground Structure (DGS) at $2.45 \mathrm{GHz}$ and $5.8 \mathrm{GHz}$ on the stacked substrate configuration in the order of FR-4 - PDMS- FR-4. The antenna offers a promising solution for wearable applications in the ISM bands. The first substrate is a flexible Flame Retardant 4 (FR-4) and the other substrate is a highly flexible Polydimethyl Siloxane (PDMS). The size of the antenna was reduced from $50 \times 50 \mathrm{~mm}^{2}$ to $30 \times 30 \mathrm{~mm}^{2}$, by introducing DGS on the ground plane. A single U-slot on the rectangular radiating patch was introduced to produce the upper resonant frequency of $5.8 \mathrm{GHz}$ while the existing square patch is to generate the lower resonant frequency of $2.45 \mathrm{GHz}$. The simulations on the dual-band dual-mode microstrip patch antenna shows the reflection coefficient, $\mathrm{S}_{11}$ at $2.45 \mathrm{GHz}$ is $-17.848 \mathrm{~dB}$ with a bandwidth of $278.8 \mathrm{MHz}$ and $-13.779 \mathrm{~dB}$ with a bandwidth of $273 \mathrm{MHz}$ at $5.8 \mathrm{GHz}$. A unidirectional radiation pattern observed in the $E$-plane shows that the antenna could be applied for off-body communication while an omnidirectional radiation pattern in the $H$-plane showed that the antenna can be used for on-body communication. Bending investigation were performed for the antenna over a vacuum cylinder with varying diameters of $50 \mathrm{~mm}, 60 \mathrm{~mm}, 70 \mathrm{~mm}, 80 \mathrm{~mm}, 90 \mathrm{~mm}, 100 \mathrm{~mm}$ and $120 \mathrm{~mm}$ in the CST MWS® software. From the graph of reflection coefficients, the performance of the antenna were not affected in bending condition. The SAR simulations showed that the SAR limits obey the guidelines as stipulated by the Federal Communication Commission (FCC) and the International Commission on Non-Ionizing Radiation Protection (ICNIRP) for $1 \mathrm{~mW}$ of input power. The $2.45 \mathrm{GHz}$ SAR limit for $1 \mathrm{~g}$ of human tissue is $0.09007 \mathrm{~W} / \mathrm{kg}$ (FCC standard: < $1.6 \mathrm{~W} / \mathrm{kg}$ ) while for $10 \mathrm{~g}$ is $0.01867 \mathrm{~W} / \mathrm{kg}$ (ICNIRP standard: $<2 \mathrm{~W} / \mathrm{kg}$ ). For $5.8 \mathrm{GHz}$, the SAR limit for $1 \mathrm{~g}$ of human tissue is $0.115 \mathrm{~W} / \mathrm{kg}$ and for $10 \mathrm{~g}$ is $0.03517 \mathrm{~W} / \mathrm{kg}$. Based on the performance of the antenna in bending condition and the SAR limits, it is safe to conclude that the antenna can be used for wearable applications at $2.45 \mathrm{GHz}$ and 5.8 $\mathrm{GHz}$ of the ISM bands.
\end{abstract}

Keywords: Microstrip patch antenna, Dual-band, Dual-mode, Defected Ground Structure (DGS)

\section{Introduction}

Flexible displays, wearable products and smart tags are a few examples of flexible electronics that were developed over the last ten years and more to come over the coming years. The presence of wearable electronics, has in a way, 
brought a significant impact in wearable and flexible antenna designs. Numerous antennas which are intended for wearable applications have been proposed as a part of a mobile communication system such as a remote healthcare monitoring system [1]. As a wearable device, the antenna needs to be highly flexible, lightweight, easy to fabricate and has no harmful effects to human as it is placed either on or away from the human body. Other than that, it is expected to be robust to various environmental changes such as wetness, heat and bending condition. For that reason, various semi-flexible and flexible substrates have been implemented in designing and fabricating the wearable antennas [2-4]. Polymers such as Polydimethylsiloxane (PDMS) due to its high flexibility and conformal to human body so as not to cause discomfort to the patients or intended users [5-6]. Flame Retardant-4 (FR-4) used to be a rigid substrate material due to its thickness of $1.6 \mathrm{~mm}$. However, the manufacturer of FR-4 has produced a much thinner FR-4 recently, with a thickness of $0.3 \mathrm{~mm}$, which makes it feasible to be used for wearable applications due to its flexibility.

The Industrial, Scientific and Medical (ISM) frequency bands, $2.45 \mathrm{GHz}$ and $5.8 \mathrm{GHz}$ are reserved internationally for the non-commercial usage in the Industrial, Scientific and Medical purposes rather than telecommunications [7]. Based on [8], the dual-band antennas operating in the ISM band are gaining popularity for the on-body and off-body communication. Specific Absorption Rate (SAR) is described as a degree or rate at which energy is absorbed by the body when exposed to an electromagnetic field from an antenna [9]. The International Commission on Non-Ionizing Radiation Protection (ICNIRP) regulates that the SAR limit is $2 \mathrm{~W} / \mathrm{kg}$ averaged over $10 \mathrm{~g}$ of human tissue following the International Electrotechnical Commission (IEC) standard for wireless devices (IEC 62209-1) [10]. On the other hand, the Federal Communication Commission (FCC) requires that the SAR should be lower than $1.6 \mathrm{~W} / \mathrm{kg}$ averaged over $1 \mathrm{~g}$ of human tissue in the United States [11]. The influence of body proximity on the performance of antenna and the amount of SAR absorbed by human body are two significant on-body parameters for wearable antennas.

In this work, a miniaturized dual-band dual-mode microstrip patch antenna with DGS at $2.45 \mathrm{GHz}$ and $5.8 \mathrm{GHz}$ of the ISM bands is proposed to overcome the limitations of the antenna operating at only a single frequency of $2.45 \mathrm{GHz}$. Furthermore, instead of working only on body, the proposed antenna is also designed to work off body for dual-mode operation. The performance of the antenna in bending condition and SAR simulations are also conducted to ensure the antenna can be used for wearable applications.

\section{Research Methodology}

This section explains the method used in order to obtain the results of the work, starting from the design stage until the simulation stage. Due to the current Movement Control Order (MCO) imposed by the Government to curb the spread of COVID-19 in Malaysia, the nature of this work is purely simulation-based.

\subsection{Antenna Design and Configuration}

The wearable antennas are designed and simulated using CST MWS $®$ software. The dimensions of the antennas are optimized to achieve the best results. At the early stage, the microstrip patch antenna is designed to operate at 2.45 $\mathrm{GHz}$ and this antenna acts as the fundamental antenna where the slot and Defected Ground Structure (DGS) are added at the next design stages to generate a dual-band operation and miniaturized the antenna.

\subsection{Design of the Microstrip Patch Antenna at $2.45 \mathrm{GHz}$}

In the first design, the antenna is designed to operate at $2.45 \mathrm{GHz}$ based on the calculation method [12]. The initial size of the antenna is $56 \times 56 \mathrm{~mm}^{2}$. The FR-4 and PDMS are stacked together as the PDMS are highly flexible and needs to be supported by a slightly rigid material. Figure shows the proposed microstrip patch antenna with FR-4 and PDMS which are stacked together in the order of FR-4 - PDMS - FR-4. The FR-4 has a dielectric constant, $\varepsilon_{r}$ of 4.5 , loss tangent, $\tan \delta$ of 0.019 and thickness, $h$ of $0.3 \mathrm{~mm}$ while PDMS has an $\varepsilon_{r}$ of $2.65, \tan \delta$ of 0.02 and $h$ of $2 \mathrm{~mm}$. The total thickness of the substrates in stacked configuration is $2.6 \mathrm{~mm}$. The proposed microstrip patch antenna at $2.45 \mathrm{GHz}$ can be seen in Fig. 1. Dimensions of the antenna (based on the calculation method) are listed in Table 1.

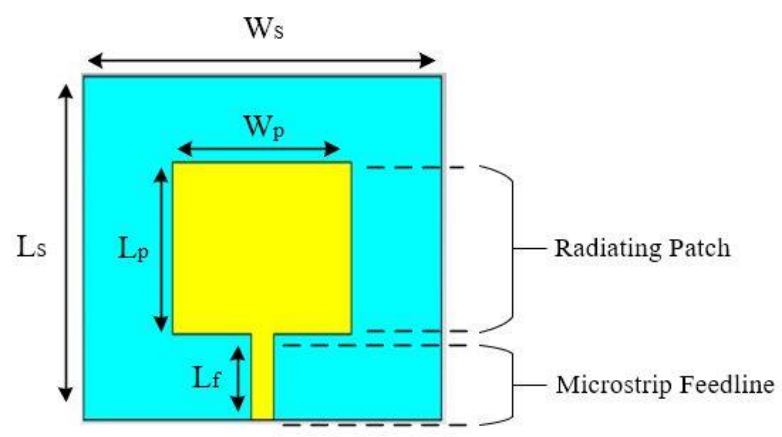

(a)

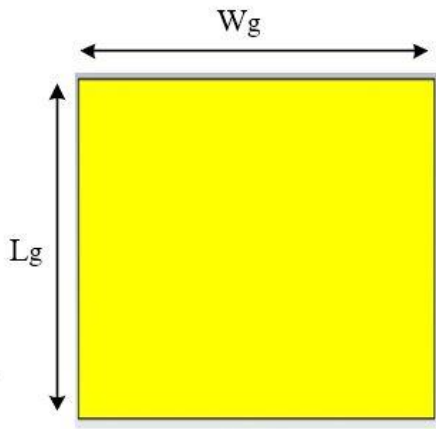

(b)

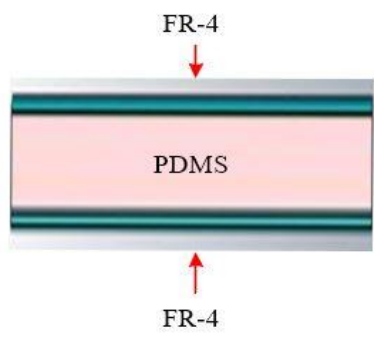

(c) 
Fig. 1 - The proposed microstrip patch antenna at $2.45 \mathrm{GHz}$

Table 1 - Dimensions of the microstrip patch antenna at $2.45 \mathrm{GHz}$ (based on the calculation method)

\begin{tabular}{cccc}
\hline Parameter & Values $(\mathbf{m m})$ & Parameter & Values (mm) \\
\hline $\mathrm{W}_{\mathrm{s}}$ & 56 & $\mathrm{~W}_{\mathrm{f}}$ & 4.90 \\
$\mathrm{~L}_{\mathrm{s}}$ & 56 & $\mathrm{~W}_{\mathrm{g}}$ & 56 \\
$\mathrm{~W}_{\mathrm{p}}$ & 35.90 & $\mathrm{Lg}_{\mathrm{g}}$ & 56 \\
$\mathrm{~L}_{\mathrm{p}}$ & 35.90 & $\mathrm{~W}_{\mathrm{fi}}$ & 1 \\
$\mathrm{~L}_{\mathrm{f}}$ & 44.50 & $\mathrm{~L}_{\mathrm{fi}}$ & 11.5 \\
\hline
\end{tabular}

\subsection{Design of Miniaturized Microstrip Patch Antenna with a Slot and DGS}

In the second stage, a slot is introduced on the radiating microstrip patch to introduce upper resonant frequency at 5.8 GHz. Fig. 2 shows the microstrip patch antenna with a U-slot on the radiating patch and Table 2 lists the dimensions of the U-slot.

In order to miniaturize the size of the antenna, DGS is introduced on the ground plane of the fundamental antenna at $2.45 \mathrm{GHz}$. The DGS design stage consists of five stages starting from a pair of inverted U-shaped, a pair of inverted F-shaped, a single slot connecting a pair of inverted U-shaped and inverted F-shaped followed by two slots and three slots. Fig. 3 until Fig. 7 shows the DGS design stages. Table 3 lists the final dimensions of the DGS on the ground plane of the antenna.

In the final antenna design, the antenna is further miniaturized from the presence of DGS to $30 \times 30 \mathrm{~mm}^{2}$ from the initial size of $56 \times 56 \mathrm{~mm}^{2}$. Fig. 8 shows the final design of the antenna. A stub is added to the antenna's feed line in order to improve the reflection coefficient. Fig. 9 shows the enlarged view of the stub and the dimensions are listed in Table 4. For the sake of simplicity, the final antenna design is called 'Miniaturized Dual-Band Dual-Mode Microstrip Patch antenna with DGS' and is used from this point onwards.

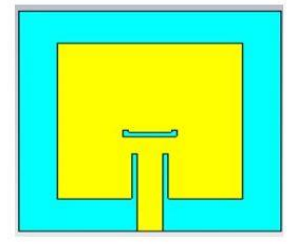

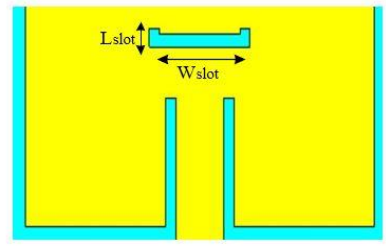

(b)
Fig. 2 - Microstrip patch antenna with a U-slot

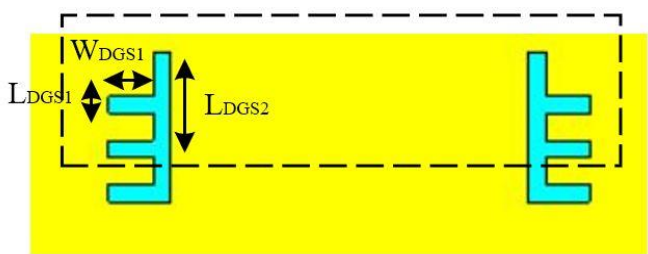

Fig. 4 - Microstrip patch antenna with a pair of inverted U-shaped and inverted F-shaped DGS

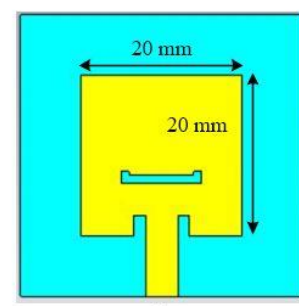

(a)

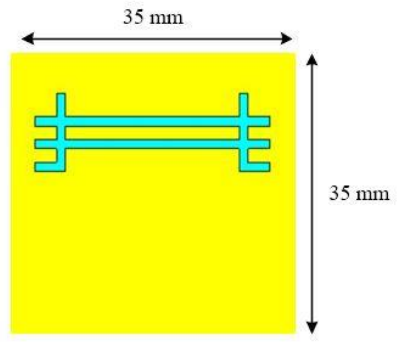

(b)
Fig. 6 - Two slots connecting a pair of inverted U-shaped and inverted F-shaped DGS
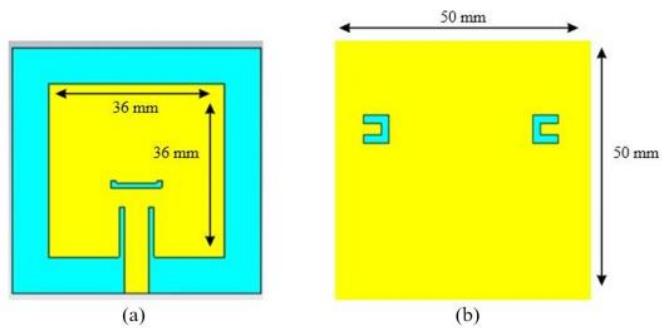

Fig. 3 - Microstrip patch antenna with a pair of inverted U-shaped DGS

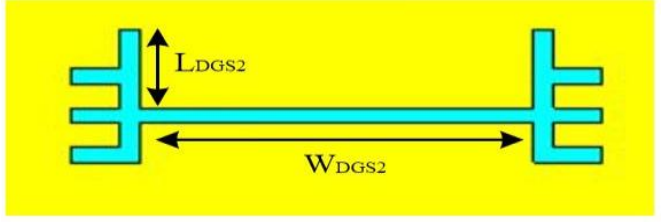

Fig. 5 - A single slot DGS connecting a pair of Inverted U-shaped and inverted F-shaped DGS
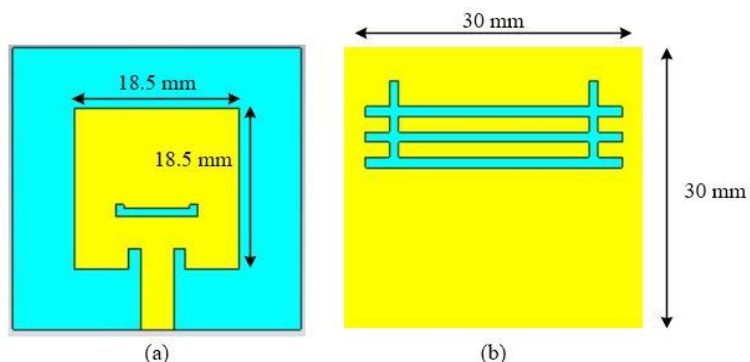

(b)

Fig. 7 - Three slots connecting a pair of inverted U-shaped and inverted F-shaped DGS 


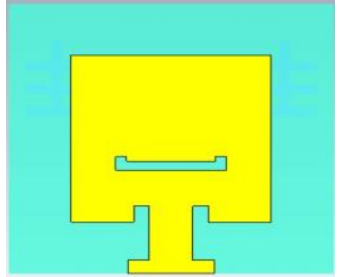

Fig. 8 - Miniaturized dual-band dual mode microstrip patch antenna with DGS

Table 2 - Dimension of the U-slot on the radiating patch

\begin{tabular}{cc}
\hline Parameter & Values $(\mathbf{m m})$ \\
\hline $\mathrm{L}_{\text {slot }}$ & 2 \\
$\mathrm{~W}_{\text {slot }}$ & 10.2 \\
\hline
\end{tabular}

Table 3 - Dimension of the three slots connecting a pair of inverted U-shaped and inverted F-shaped DGS (final design of DGS on the ground plane based on Fig. 7)

\begin{tabular}{cccc}
\hline Parameter & Values $(\mathbf{m m})$ & Parameter & Values $(\mathbf{m m})$ \\
\hline $\mathrm{W}_{\mathrm{g}}$ & 30 & $\mathrm{~W}_{\text {DGS1 }}$ & 3 \\
$\mathrm{~L}_{\mathrm{g}}$ & 30 & $\mathrm{~W}_{\text {DGS2 }}$ & 15 \\
$\mathrm{~W}_{\mathrm{p}}$ & 18.5 & $\mathrm{LDGS}$ & 2 \\
$\mathrm{~L}_{\mathrm{p}}$ & 18.5 & $\mathrm{~L}_{\mathrm{DGS} 2}$ & 10 \\
\hline
\end{tabular}

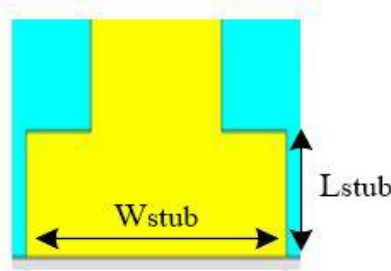

Fig. 9 - Enlarged view of the stub

Table 4 - Dimensions of the stub

\begin{tabular}{cc}
\hline Parameter & Values $(\mathbf{m m})$ \\
\hline $\mathrm{L}_{\text {stub }}$ & 2 \\
$\mathrm{~W}_{\text {stub }}$ & 6 \\
\hline
\end{tabular}

\subsection{Antenna Simulation in Bending Condition}

A vacuum cylinder along $y$-axis is created to perform a bending investigation as shown in Fig. 10. The CST MWS ${ }^{\circledR}$ software is used to simulate the bending of the antenna over a vacuum cylinder with varying diameters of $50 \mathrm{~mm}, 60 \mathrm{~mm}, 70 \mathrm{~mm}, 80 \mathrm{~mm}, 90 \mathrm{~mm}, 100 \mathrm{~mm}$ and $120 \mathrm{~mm}$. The sizes of the cylinder are selected based on different sizes of human arms.

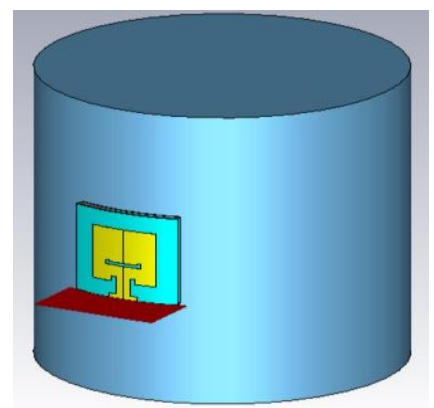

Fig. 10 - Antenna's bending over a vacuum cylinder in CST MWS® software

\section{Results and Analysis}

In this section, the linear characteristics of the miniaturized dual-band dual-mode microstrip patch antenna, which is the final antenna design are discussed and analyzed. In addition, the performance of the antenna in bending condition and the SAR simulations are also examined to ensure the antenna could be used for wearable applications.

\subsection{Reflection Coefficient and Bandwidth}

The simulated reflection coefficient of the miniaturized dual-band dual mode microstrip patch antenna with DGS can be viewed in Fig. 11. From the figure, the reflection coefficient, $S_{11}$ of the antenna are $-17.848 \mathrm{~dB}$ and $-13.779 \mathrm{~dB}$ at $2.45 \mathrm{GH}$ and $5.8 \mathrm{GHz}$, respectively. The $-10-\mathrm{dB}$ bandwidth, on the other hand, are $278.8 \mathrm{MHz}$ and $273 \mathrm{MHz}$ at each resonant frequency. 


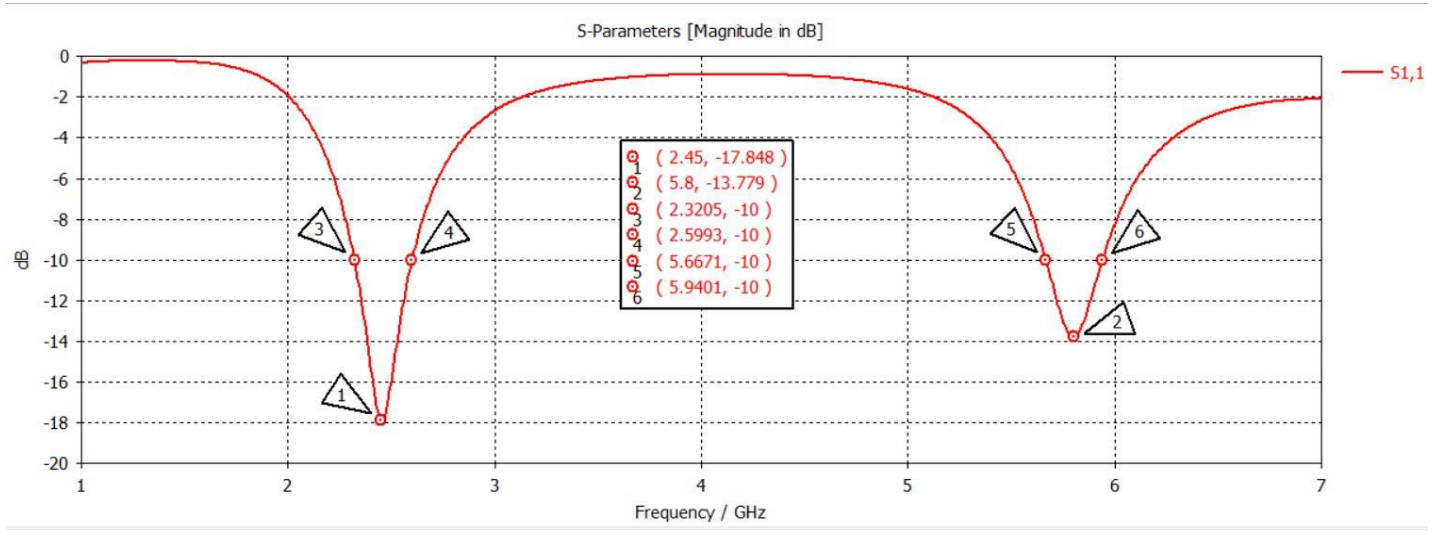

Fig. 11 - Reflection coefficient of the miniaturized dual-band dual-mode microstrip patch antenna with DGS at $2.45 \mathrm{GHz}$ and $5.8 \mathrm{GHz}$

\subsection{Voltage Standing Wave Ratio (VSWR)}

Fig. 12 shows the simulated Voltage standing Wave Ratio of the miniaturized dual-band dual-mode microstrip patch antenna with DGS at $2.45 \mathrm{GHz}$ and $5.8 \mathrm{GHz}$. From the figure, it can be observed that the VSWR at $2.45 \mathrm{GHz}$ is 1.2939 and at $5.8 \mathrm{GHz}$ is 1.5146 . VSWR $\leq 2.0$ shows the antenna operates well at both resonant frequencies.

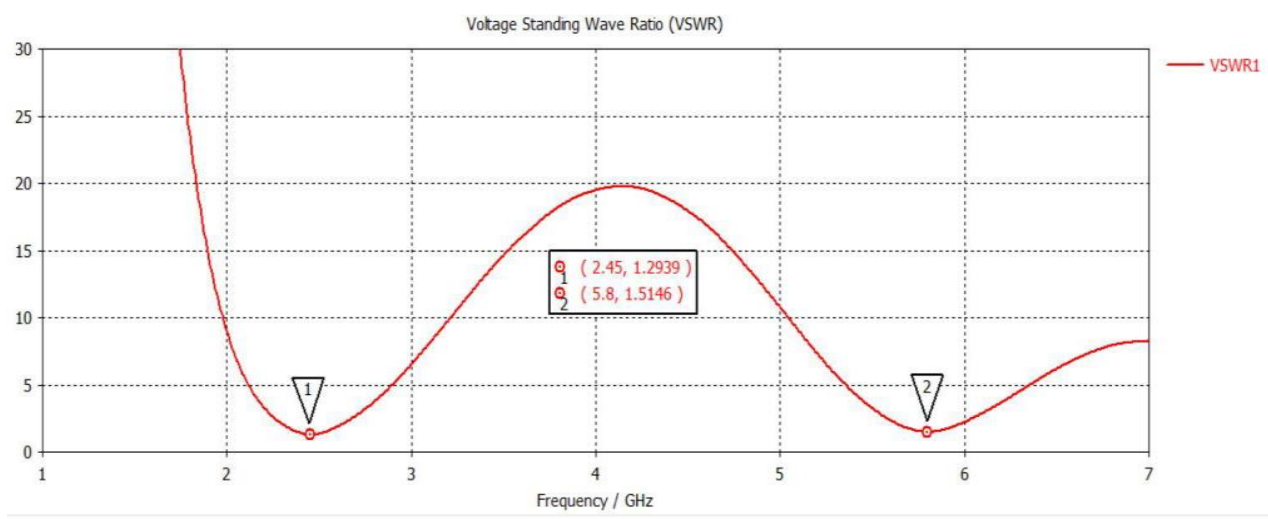

Fig. 12 - VSWR of the miniaturized dual-band dual-mode microstrip patch antenna with DGS

\subsection{Radiation Patterns}

The radiation patterns of the miniaturized dual-band dual-mode microstrip patch antenna with DGS at $2.45 \mathrm{GHz}$ and $5.8 \mathrm{GHz}$ can be seen in Fig. 13 and Fig. 14. From Fig. 13(a), a unidirectional radiation pattern in the E-plane at $2.45 \mathrm{GHz}$ is desirable for off-body communication while in Fig. 13(b), an omnidirectional radiation pattern observed in the $H$-plane shows that the antenna can be used for on-body communication [13]. Similarly, at $5.8 \mathrm{GHz}$, a unidirectional radiation pattern in the $E$-plane and omnidirectional radiation pattern in the $H$-plane shows that the antenna is capable to be used for off-body and on-body communication.

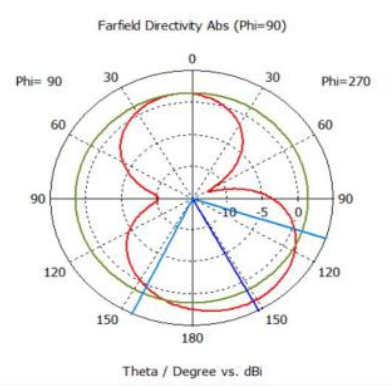

(a)

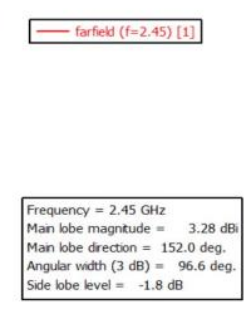

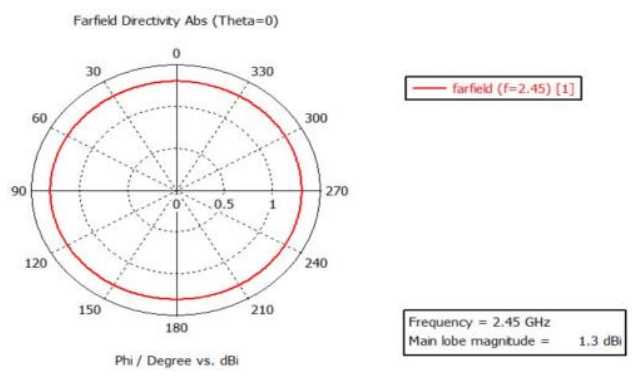

(b)

Fig. 13 - Radiation patterns of the miniaturized dual-band dual-mode microstrip patch antenna with DGS at $2.45 \mathrm{GHz}$ in the: (a) $E$-plane; (b) $H$-plane 


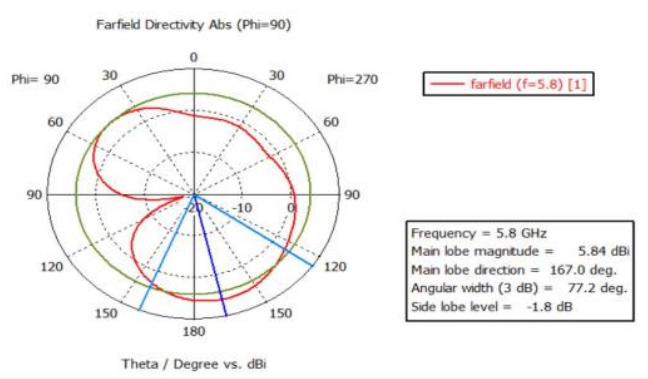

(a)

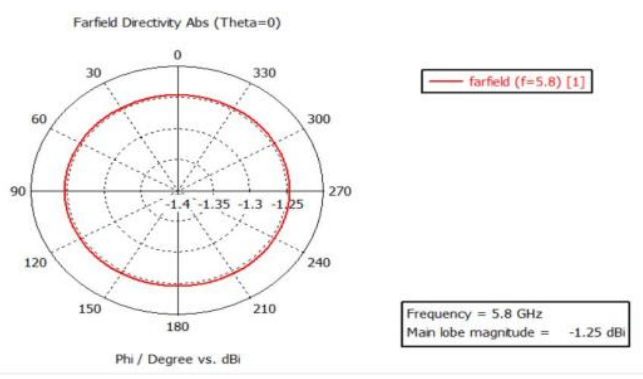

(b)

Fig. 14 - Radiation patterns of the miniaturized dual-band dual-mode microstrip patch antenna with DGS at $5.8 \mathrm{GHz}$ in the: (a) $E$-plane; (b) $H$-plane

\subsection{Gain and Efficiency}

The gain and efficiency of the miniaturized dual-band dual-mode microstrip patch with DGS can be viewed in Fig. 15. From Fig. 15(a), the gain, $G$ of the antenna at $2.45 \mathrm{GHz}$ is $3.270 \mathrm{dBi}$ and $5.834 \mathrm{dBi}$ at $5.8 \mathrm{GHz}$ as can be seen in Fig. 15(b). On the other hand, the efficiency, $\eta(\%)$ at $2.45 \mathrm{GHz}$ is $55.55 \%$ and $59.90 \%$ at $5.8 \mathrm{GHz}$, which are acceptable for the operation of the dual-band antenna.

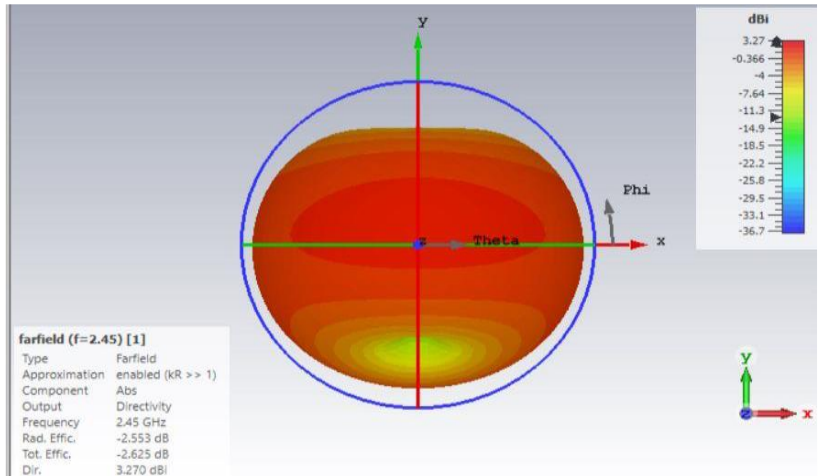

(a)

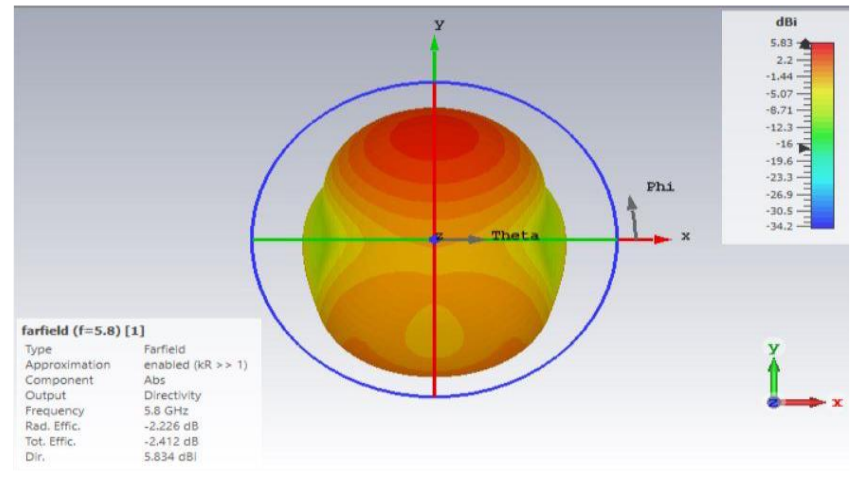

(b)

Fig. 15 - Gain and efficiency of the miniaturized dual-band dual-mode microstrip patch antenna with DGS at: (a) $2.45 \mathrm{GHz}$; (b) $5.8 \mathrm{GHz}$

\subsection{Surface Current Distribution}

Fig. 16 shows the surface current distribution of the miniaturized dual-band dual-mode microstrip patch antenna with DGS at $2.45 \mathrm{GHz}$ and $5.8 \mathrm{GHz}$. From Fig. 16(a), maximum current at $2.45 \mathrm{GHz}$ is concentrated around the edges of rectangular patch and around the pair of inverted U-shaped and F-shaped DGS. These show that the patch and DGS are responsible to radiate electromagnetic waves from the antenna at $2.45 \mathrm{GHz}$. From Fig. 16(b), maximum current at $5.8 \mathrm{GHz}$ is concentrated around the edges of the U-slot on the radiating patch. This shows that the slot is responsible in generating the upper resonant frequency of $5.8 \mathrm{GHz}$. 


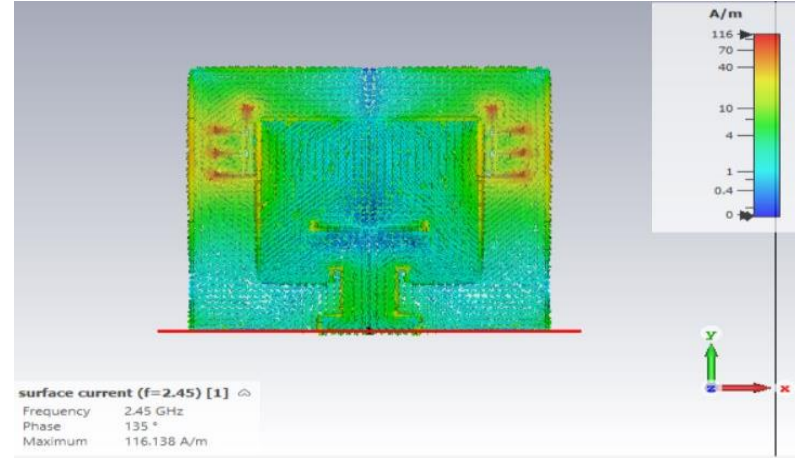

(a)

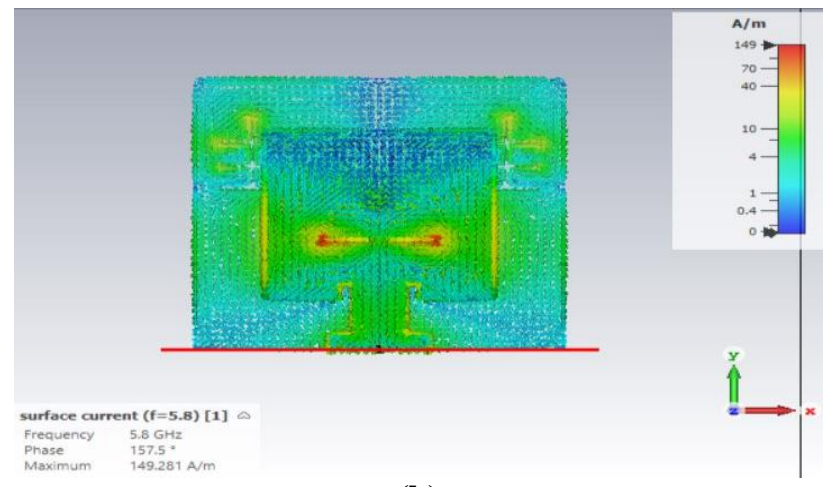

(b)

Fig. 16 - Surface current distribution of the miniaturized dual-band dual-mode microstrip patch antenna with DGS at: (a) $2.45 \mathrm{GHz}$; (b) $5.8 \mathrm{GHz}$

\subsection{Bending Investigation}

Fig. 17 shows the comparison of simulated reflection coefficients of the antenna for all diameters of vacuum cylinder. It can be observed from the figure that the performance of the antenna is not affected in bending condition since the reflection coefficients are almost similar. Table 5, on the other hand, compares the numerical values of the simulated reflection coefficients of the antenna for all diameters of vacuum cylinder at $2.45 \mathrm{GHz}$ and $5.8 \mathrm{GHz}$.

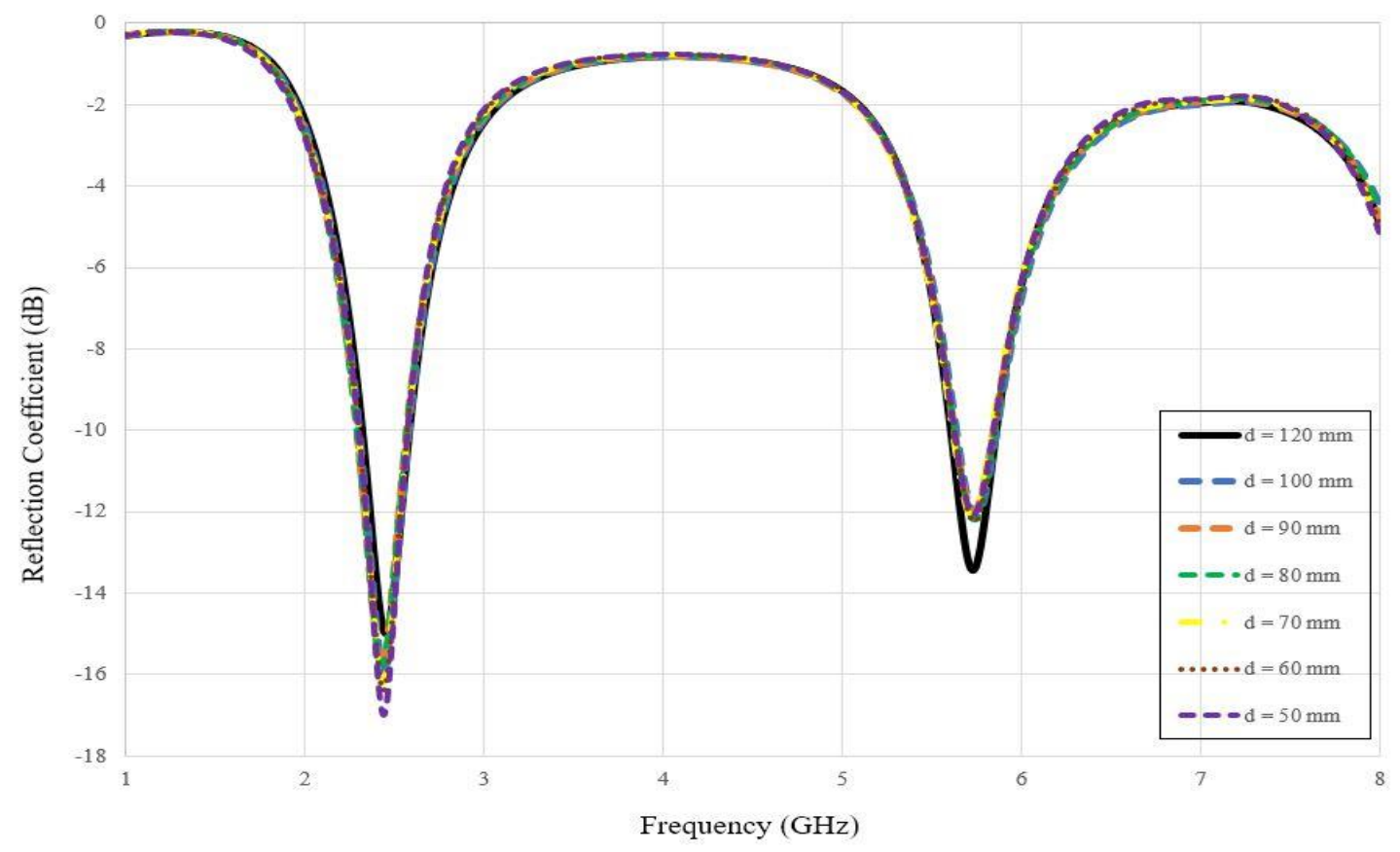

Fig. 17 - Simulated reflection coefficients of the antenna in bending condition for different diameters of vacuum cylinder at $2.45 \mathrm{GHz}$ and $5.8 \mathrm{GHz}$

Table 5 - Numerical values of simulated reflection coefficients of antenna in bending condition for different diameter of vacuum cylinder at $2.45 \mathrm{GHz}$ and $5.8 \mathrm{GHz}$

\begin{tabular}{ccc}
\hline Diameters $(\mathbf{m m})$ & $\mathbf{S}_{\mathbf{1 1}}$ at $\mathbf{2 . 4 5} \mathbf{~ G H z}(\mathbf{d B})$ & $\mathbf{S}_{\mathbf{1 1}}$ at $\mathbf{5 . 8 ~ G H z}(\mathbf{d B})$ \\
\hline 50 & -16.846 & -11.161 \\
60 & -16.237 & -11.439 \\
70 & -16.034 & -10.922 \\
80 & -15.413 & -11.414 \\
90 & -15.531 & -11.121 \\
100 & -15.830 & -11.531 \\
120 & -14.982 & -12.032 \\
\hline
\end{tabular}




\subsection{Specific Absorption Rate}

In the Specific Absorption Rate (SAR) simulation, $1 \mathrm{~mW}$ of input power to the antenna is chosen as it is commonly practiced [14]. The antenna is located at $2 \mathrm{~mm}$ above the numerical phantom to compensate for the thickness of a fabric if the antenna is to be worn on body. IEEE C95.3 is used based on the provided standard for SAR calculation in CST MWS® software. The SAR simulations of the miniaturized dual-band dual-mode microstrip patch antenna at $2.45 \mathrm{GHz}$ and $5.8 \mathrm{GHz}$ can be seen in Fig. 18 and Fig. 19. From Fig. 18(a), at 2.45 GHz, the SAR limits of the antenna is $0.09007 \mathrm{~W} / \mathrm{kg}$ at $1 \mathrm{~g}$ of human tissue and $0.01867 \mathrm{~W} / \mathrm{kg}$ at $10 \mathrm{~g}$ as in Fig. 18(b). On the other hand, the SAR limits of the antenna at $5.8 \mathrm{GHz}$ is $0.115 \mathrm{~W} / \mathrm{kg}$ at $1 \mathrm{~g}$ of human tissue and $0.003517 \mathrm{~W} / \mathrm{kg}$ at $10 \mathrm{~g}$ as can be viewed from Fig. 19(a) and 19(b). Therefore, $1 \mathrm{~mW}$ of input power to the antenna obeys the SAR guidelines by the FCC and ICNIRP.

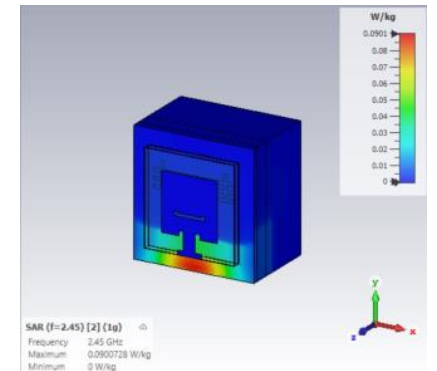

(a)

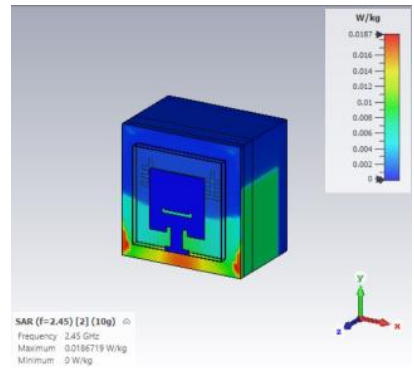

(b)

Fig. 18 - Simulated SAR values for the miniaturized dual-band dual mode microstrip patch antenna with DGS at 2.45 GHz for: (a) $1 \mathrm{~g}$ of human tissue; (b) $10 \mathrm{~g}$ of human tissue

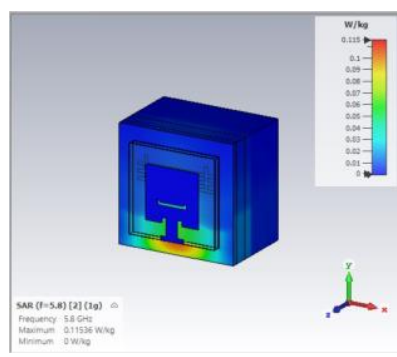

(a)

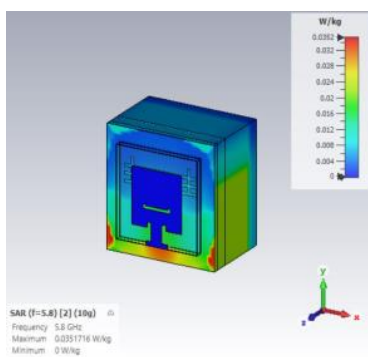

(b)

Fig. 19 - Simulated SAR values for the miniaturized dual-band dual mode microstrip patch antenna with DGS at $5.8 \mathrm{GHz}$ for: (a) $1 \mathrm{~g}$ of human tissue; (b) $10 \mathrm{~g}$ of human tissue

\section{Conclusion}

A miniaturized dual-band dual-mode microstrip patch antenna with Defected Ground Structure (DGS) for wearable applications at $2.45 \mathrm{GHz}$ and $5.8 \mathrm{GHz}$ is presented in this work. The antenna uses two different substrate materials in stacked configuration which are the thin bendable Flame Retardant-4 (FR-4) and highly flexible Polydimethyl Siloxane (PDMS), in the order of FR-4 - PDMS - FR-4. The antenna was simulated in CST MWS $®$ software. The size of the antenna was further reduced from $50 \times 50 \mathrm{~mm} 2$ to the final dimension of $30 \times 30 \mathrm{~mm}^{2}$ (accounted for $40 \%$ of size reduction) by introducing DGS on the ground plane. The simulated reflection coefficient, $\mathrm{S}_{11}$ at $2.45 \mathrm{GHz}$ is $-17.848 \mathrm{~dB}$ with a bandwidth of $278.8 \mathrm{MHz}$ and $-13.779 \mathrm{~dB}$ with a bandwidth of $273 \mathrm{MHz}$ at 5.8 $\mathrm{GHz}$. A unidirectional radiation pattern observed in the $E$-plane showed that the antenna could be applied for off-body communication while an omnidirectional radiation pattern in the $H$-plane showed that the antenna can be used for onbody communication. Bending investigation were performed for the antenna over a vacuum cylinder with varying diameters of $50 \mathrm{~mm}, 60 \mathrm{~mm}, 70 \mathrm{~mm}, 80 \mathrm{~mm}, 90 \mathrm{~mm}, 100 \mathrm{~mm}$ and $120 \mathrm{~mm}$ in the CST MWS® software. It is shown from the reflection coefficients that the performance of the antenna was not affected in bending condition. The SAR was simulated to ensure that the antenna follows the requirements by the FCC and ICNIRP. Based on the SAR simulations, it is also shown that the antenna obeys the guidelines for $1 \mathrm{~mW}$ of input power to the antenna. The SAR limits at $2.45 \mathrm{GHz}$ for $1 \mathrm{~g}$ of human tissue is $0.09007 \mathrm{~W} / \mathrm{kg}$ (FCC standard: $<1.6 \mathrm{~W} / \mathrm{kg}$ ) while for $10 \mathrm{~g}$ is $0.01867 \mathrm{~W} / \mathrm{kg}$ (ICNIRP standard: $<2 \mathrm{~W} / \mathrm{kg}$ ). On the other hand, the SAR limits at $5.8 \mathrm{GHz}$ for $1 \mathrm{~g}$ of human tissue is at $0.115 \mathrm{~W} / \mathrm{kg}$ and for $10 \mathrm{~g}$ is at $0.03517 \mathrm{~W} / \mathrm{kg}$. Therefore, it can be concluded that the antenna could be used for wearable applications based on the findings obtained from the bending condition and SAR limits. 


\section{References}

[1] R. B. V. B. Simorangkir, Y. Yang, L. Matekovits, \& K. P. Esselle. (2016). Dual-Band Dual-Mode Textile Antenna on PDMS Substrate for Body-Centric Communications. IEEE Antennas Wirel. Propag. Lett., 16, 677680

[2] M. Klemm \& G. Troester. (2006). Textile UWB Antennas for Wireless Body Area Networks. IEEE Trans. Antennas Propag., 54, 3192-3197

[3] P. J. Soh, G. A. E. Vandenbosch, M. Mercuri, \& D. M. M. P. Schreurs. (2015). Wearable Wireless Health Monitoring: Current Developments, Challenges, and Future Trends. IEEE Microw. Mag., 16, 55-70

[4] H. M. A. Fahmy. (2016). Wireless Sensor Networks. Concepts, Applications, Experimentation and Analysis (1st ed). Singapore: Springer

[5] C. Mendes \& C. Peixeiro. (2017). A Dual-Mode Single-Band Wearable Microstrip Antenna for Body Area Networks. IEEE Antennas Wirel. Propag. Lett., 16, 3055-3058

[6] J. Tak, S. Woo, J. Kwon, \& J. Choi. (2016). Dual-Band Dual-Mode Patch Antenna for On-/Off-Body WBAN Communications. IEEE Antennas Wirel. Propag. Lett., 15, 348-351

[7] C. P. Lin, C. H. Chang, Y. T. Cheng, \& C. F. Jou. (2011). Development of a Flexible SU-8/PDMS-based Antenna. IEEE Antennas Wirel. Propag. Lett., 10, 1108-1111

[8] K. Zhao, S. Zhang, Z. Ying, T. Bolin, \& S. He. (2012). SAR Study of Different MIMO Antenna Designs for LTE Application in Smart Mobile Phones. Proceedings of the 2012 IEEE Trans. Antennas Propag. Chicago, USA

[9] A. H. Kusuma, A. F. Sheta, I. Elshafiey, Z. Siddiqui, M. Alkanhal, S. Aldosari, S. A. Alshebeili, \& S. Mahmoud. (2011). A New Low SAR Antenna Structure for Wireless Handset Applications. Prog. Electromagn. Res

[10] Q. H. Abbasi, M. U. Rehman, X. Yang, A. Alomainy, K. Qaraqe, \& E. Serpedin. (2013). Ultrawideband BandNotched Flexible Antenna for Wearable Applications. IEEE Antennas Wirel. Propag. Lett., 12, 1606-1609

[11] C. -H. Lin \& K. Ito. (2014). Dual-Mode Wearable Antenna for On/Off-Body Wireless Communications. 2014 International Workshop on Antenna Technology: Small Antennas, Novel EM Structures and Materials, 286287

[12] R. Kapur. (2016). Microstrip Patch Antenna Calculator. Everything RF. http://www.everythingrf.com/rfcalculators/microstrip-patch-antenna-calculator (accessed Jun. 19, 2021)

[13] H. Xiaomu, S. Yan, \& G. A. E. Vandenbosch. (2017). Wearable Button Antenna for Dual-Band WLAN Applications with Combined On and Off-Body Radiation Patterns. IEEE Trans. Antennas Propag., 65, 13841387

[14] R. Pethig. (1984). Dielectric properties of biological materials: Biophysical and Medical Applications. IEEE Trans. Electr. Insul., EI-19, 453-474 